\title{
Effect of a dragonfly (Bradinopyga strachani Kirby, 1900) on the density of mosquito larvae in a field experiment using mesocosms
}

\author{
Daniel Acquah-Lamptey and Roland Brandl \\ Faculty of Biology, Department of Ecology-Animal Ecology, Philipps Universität Marburg, \\ Karl-von-Frisch-Strasse 8, 35043 Marburg, Germany \\ Correspondence: Daniel Acquah-Lamptey (dacquahlamptey@gmail.com)
}

Received: 22 January 2018 - Revised: 9 April 2018 - Accepted: 25 April 2018 - Published: 24 May 2018

\begin{abstract}
Laboratory experiments with food-deprived larvae of odonates suggested that these predators may have the potential to control mosquito populations. However, it remains unclear whether larvae of odonates cooccur with mosquito larvae in the field and whether larvae of odonates reduce the density of mosquito larvae in the field. We exposed 35 water-filled concrete containers in the field in shady and sunny conditions. Some of these containers were partially covered (for simplicity called closed containers, allowing only mosquitoes to lay eggs), whereas others remained open. The density of mosquito larvae was higher in shaded containers and in closed containers. The multivoltine odonate Bradinopyga strachani colonized open containers and the occurrence of these predators resulted in a clear reduction of the mosquito population. Our results indicate that increasing the colonization of water bodies by Bradinopyga strachani is a promising strategy for controlling populations of mosquitoes.
\end{abstract}

\section{Introduction}

Mosquitoes are vectors of severe diseases, such as malaria, yellow fever, chikungunya, dengue fever, lymphatic filariasis, Rift Valley fever, and Zika fever (World Health Organization, 2016a). The main vectors of these diseases are species of the nematoceran genera Aedes, Culex and Anopheles (World Health Organization, 2016a). Each year, over a million deaths occur and several hundred million people worldwide suffer from mosquito-borne diseases (World Health Organization, 2013, 2016b, c, d, 2017). In Africa, dengue fever is endemic in 34 countries, 35 countries have a high risk of yellow fever, lymphatic filariasis is endemic in 39 countries and 188 million cases of malaria occur across the entire region (World Health Organization, 2013, 2016b, c, $d, 2017)$. In Ghana, malaria alone is responsible for about 14000 deaths of children per year (Ministry of Health \& Ghana Health Service, 2013). Treatment of these mosquitoborne diseases comes at a substantial cost (Kokwaro, 2009) and the vaccination against malaria has had little success (Gosling and Von Seidlein, 2016). Furthermore, the mosquito vectors are resistant to insecticides (Kelly-Hope et al., 2005; Mawejje et al., 2013; Kudom et al., 2015a, b), and the pesticides also affect non-target species (Ware, 1980). Hence, affordable and environmentally friendly methods of controlling larval (and adult) mosquitoes need to be developed.

One strategy that has shown some potential in reducing the density of mosquito larvae is the use of various lineages of predators such as crustaceans, fish, amphibians and also odonates (dragonflies and damselflies; Table 1). The aquatic larvae of odonates can co-occur with the larvae of mosquitoes. Several studies of odonate predation on mosquito larvae have used food-deprived individuals of the predator (e.g. Venkatesh and Tyagi, 2013a, b; Saha et al., 2012; Kweka et al., 2011; Mandal et al., 2008). For instance, Kweka et al. (2011) collected odonates from breeding grounds, starved them for $12 \mathrm{~h}$ before introducing them into experimental habitats. Saha et al. (2012) collected odonates, starved them for $24 \mathrm{~h}$ in the laboratory before offering various instars of Culex quinquefasciatus to examine the functional response. Mandal et al. (2008) also collected and transported two dragonfly and three damselfly species from their 
Table 1. List of studies on predator-prey interactions between mosquito larvae and various lineages of predators.

\begin{tabular}{ll}
\hline Predator lineage & References \\
\hline Crustaceans & $\begin{array}{l}\text { Kay et al. (1992); Marten et al. (1994); Kumar and Rao (2003); } \\
\text { Panogadia-Reyes et al. (2004); Marten and Reid (2007) }\end{array}$ \\
\hline Nematodes & Mijares et al. (1999); Perez-Pacheco and Flores (2005) \\
\hline Fish & $\begin{array}{l}\text { Neng et al. (1987); Blaustein and Bryard (1993); Wang (1998); } \\
\text { Hammer et al. (2002); Mohamed (2003); Chandra et al. (2008) }\end{array}$ \\
\hline Hemipterans & Aditya et al. (2004); Saha et al. (2007); Sivagnaname (2009) \\
\hline Amphibians & Komak and Crossland (2000); Mokany and Shine (2003); Raghavendra et al. (2008) \\
\hline Coleopterans & Lundkvist et al. (2003), Aditya et al. (2004, 2006) \\
\hline Heteropterans & Rodriguez-Castro et al. (2006); Saha et al. (2007) \\
\hline Dipterans & Hechtel and Juliano (1997); Aditya et al. (2007); Nyamah et al. (2011) \\
\hline Odonates & $\begin{array}{l}\text { Mathavan (1976); Sebastian et al. (1980); Muira and Takahashi (1988); } \\
\text { Sebastian et al. (1990); Fincke et al. (1997); Stav et al. (2000); Singh et al. (2003); } \\
\text { Quiroz-Martinez et al. (2005); Stav et al. (2005); Chatterjee et al. (2007); Mandal et al. (2008); } \\
\text { Saha et al. (2009, 2012); Sathe and Bhusner (2010); Kweka et al. (2011); } \\
\text { Venkatesh and Tyagi (2013a, b); Weterings et al. (2015); Jacob et al. (2017) }\end{array}$
\end{tabular}

The listed studies involved organisms that could potentially colonize mosquito breeding habits, are able to reproduce in these habitats, and pose no danger to people (Bellows, 2001; Headrick and Goeden, 2001; Spielman et al., 1993; see reviews in Quiroz-Martinez and Rodriguez-Castro, 2007 and Kumar and Hwang, 2006). Many of the studies involving odonates were laboratory based and/or made use of starved predators (citations in bold).

natural breeding sites into the laboratory to test the efficiency of the larvae of these species in controlling Culex quinquefasciatus. However, interpretation of the results from these experimental studies suffers from various methodological limitations (reviewed in Kumar and Hwang, 2006). Despite clear indications that odonates feed on mosquito larvae, the results of such studies overestimate predation rates as well as the potential to reduce densities of mosquito larvae under field conditions (Weterings et al., 2015).

Several factors could affect the success of the biological control of mosquitoes using odonates, such as (1) the particular mosquito species and the density of mosquito larvae, (2) density, body size, and species identity of the odonate (Cordoba-Aguilar and Lee, 1994; Fincke et al., 1997; Saha et al., 2012; Weterings et al., 2015), (3) habitat and water quality (Fincke et al., 1997; Kweka et al., 2012; Varshini and Kanagappan, 2014; Akram and Ali-Khan, 2016) and (4) overlap of mosquito and odonate habitats (Chatterjee et al., 2007). Furthermore, mosquitoes breed in a wide range of habitats that are usually of low quality (Dejene et al., 2015; Kudom, 2015), e.g. rain pools, concrete tanks, and choked gutters. Therefore, species of odonates that are able to naturally breed in such low-quality habitats are potential agents for the biological control of mosquito larvae. Although odonates are known to be more effective than other predators in controlling their prey (Kumar and Hwang, 2006), it is thought that larvae of odonates and mosquitoes do not coexist naturally at high densities and that odonate larvae are not selective enough in their feeding behaviour to reduce the density of mosquito larvae (Sebastian et al., 1990). In a simple field experiment, we tested the hypothesis that odonates colonize artificial habitats like water-storage containers used in African villages and are able to reduce the density of mosquito larvae which also colonize these containers.

\section{Materials and methods}

\subsection{Study area}

The study was conducted on the research farm of the University of Ghana, Legon campus $\left(5^{\circ} 39^{\prime} 28.7^{\prime \prime} \mathrm{N} 0^{\circ} 11^{\prime} 31.6^{\prime \prime} \mathrm{W}\right)$, which lies within the main university campus, $13 \mathrm{~km}$ northeast of the capital Accra. The 29 ha farm is characterized by natural grass fields, irrigated vegetable fields and widely interspersed trees of mango and cashew. The experiment was conducted between June and August 2016, when coastal regions of Ghana experience peak rainfall (annual rainfall: 733-1118 mm).

\subsection{Field experiment}

We randomly placed 18 concrete containers $(120 \mathrm{~cm} \times 60 \mathrm{~cm} \times 40 \mathrm{~cm})$ in shaded areas and $17 \mathrm{con}-$ tainers in sunlit areas. The containers were filled with ground water (Supplement Fig. S4). Ten containers (four in sunlight and six in shade) were each partially covered with a wooden board (for simplicity further on called closed 
Table 2. Summary of model estimates ( \pm standard errors (SE)). We also give the equations for the three models using the formalism of $\mathrm{R}$ (R Development Core Team, 2016).

\begin{tabular}{llll}
\hline & Model 1 & Model 2a & Model 2d \\
\hline Intercept \pm SE & $-0.01 \pm 0.80$ & $-0.40 \pm 0.76$ & $-0.34 \pm 0.15$ \\
Open containers \pm SE & $-2.71 \pm 0.97$ & $-2.67 \pm 0.90$ & $-1.61 \pm 0.15$ \\
Shaded \pm SE & $0.96 \pm 0.27$ & $0.75 \pm 0.42$ & $0.53 \pm 0.13$ \\
Open container: day \pm SE & $-1.33 \pm 0.40$ & $-1.22 \pm 0.42$ & $-0.36 \pm 0.08$ \\
AIC & 4099.7 & 3348.1 & 3583.6 \\
\hline
\end{tabular}

Model 1: number of larvae $\sim$ container + container $:$ day + shade $+(1+$ day l code $)+(1$ I count $)$

Model 2a: number of larvae $\sim$ container + container $:$ day + shade $+(1+$ day l code $)+(1$ l count $)+(1$ lobs $)$

Model 2d: number of larvae $\sim$ container + container $:$ day + shade $+(1$ lobs $)$

The factor container has two levels (open and closed), the factor shade also has two levels (shaded and sunlit), day is a continuous variables and measures the time since the start of experiment (thereby also an indirect variable for the age of larvae), count refers to repeated counts of mosquito larvae, $o b s$ refers to the observations of each individual container, code refers to the codes given to each experimental container, $(1 \mid$ count $)$ indicates a random intercept of the repeated counts, $(1 \mid \mathrm{obs})$ the random intercept for each observation, and $(1+d a y \mid$ code $)$ random slope for each container. For each model we also give the Akaike information criterion (AIC).

containers), so that only mosquitoes could gain access to the water; the remaining 25 containers were left uncovered (open containers) so that they could be colonized by both mosquitoes and odonates. Such containers are used in most rural homes and farmlands in the tropics for harvesting rain water and/or storing water for domestic use and irrigation (Amha, 2008; Nega, 2005; Rämi, 2003). When filled with water, these containers usually serve as a breeding ground for mosquitoes (Waktola, 2008).

The containers were left for two weeks to allow colonization by mosquitoes and odonates. Colonization of open containers by odonates was determined by observing the territorial behaviour of males and oviposition by females, and the presence of larvae and eventually exuviae from emerging adults. The density of mosquito larvae in each container was assessed weekly for an additional eight weeks by counting the number of larvae in six samples scooped with a $1 / \mathrm{L}$ beaker (see Mandal et al., 2008). The water level in each container was maintained by adding groundwater as necessary. At the end of the 10 weeks, 45 odonate larvae were collected from colonized open containers and reared in the laboratory with temperature varying between 24 and $32{ }^{\circ} \mathrm{C}$. Odonate larvae were kept individually in small plastic containers with a height $9 \mathrm{~cm}$ and base diameter of $9 \mathrm{~cm}$ halffilled with pond water (Fig. S4). A stick was placed in each plastic container to support adult emergence. Odonate larvae were fed on mosquito larvae until emergence and adults were identified according to Dijkstra and Clausnitzer (2014).

\subsection{Data analysis}

All analyses were conducted in $\mathrm{R}$ version 3.3.2 software ( $\mathrm{R}$ Development Core Team, 2016). To manipulate and organize the data, the package tidyr was used (Wickham, 2017). To analyse the impact of shade, container type, and time since start of the experiment on the number of mosquito larvae, we fitted generalized mixed-effects models using distributions appropriate for count data (Poisson, negative binomial; Hadfield, 2010; Supplement Table S1). As fixed effects, we fitted the factors container (open or closed), shade (shaded or sunlit) and within the factor container the continuous variable day (i.e. time from the start of the experiment). This procedure was necessary as we expected that the change in population density of the mosquito larvae differs between open containers (decreases with time, owing to predation) and closed containers (no change with time). Furthermore, we included a random slope for each container as well as a random intercept for each count (repeated count of mosquito larvae with each scoop). The random factors account for any variations that might exist between experimental containers as a result of varying microhabitat conditions and also account for the repeated counts (see model details in Tables 2, S1, S2). When a Poisson-distribution was used, model 1 showed signs of over-dispersion; therefore, we included a random effect of individual level variability to account for over-dispersion (Model 2a). However, model 2a failed to converge; therefore, we used other functions as well as error distributions to test whether the estimates were robust (Tables S1, S2). Overall, we tested nine models but since all models produced similar results (Tables S1, S3, Fig. S5), we present results of the reduced model $2 \mathrm{~d}$ (results of other models are presented in Table S2). Using the model.sel function (Barton, 2015) in the R-package MuMln, model $2 \mathrm{~d}$ was the best selected from the converging models (Table S3).

\section{Results}

Mosquitoes (Aedes, Culex) began to colonize the containers a week after the start of the experiment. Colonization of the containers by odonates also commenced at this time with the incidence of an ovipositing female Bradinopyga strachani (Family Libellulidae). By the third week after the start of the experiment, $21(84 \%)$ of the open containers were col- 
onized by odonate larvae; all 14 open containers in sunlit areas and 7 in shaded areas. Although five dragonfly species were observed within the study area (Palpopleura lucia, Pantala flavescens, Bradinopyga strachani, Tramea basilaris, and Orthetrum austeni), only B. strachani colonized the containers. Both $B$. strachani and $O$. austeni successfully bred in an older irrigation pond within the study area; no mosquito larvae were recorded in this pond.

Shade of the breeding site positively influenced the density of mosquito larvae (Tables 2, S2). Our results indicated also that density of mosquito larvae in open containers were lower (possible presence of dragonfly larvae) compared to closed containers. Furthermore, particularly in open containers, density of mosquito larvae decreased with the time since start of the experiment (indirect variable describing the maximum possible age of odonate larvae (Tables 2, S2).

\section{Discussion}

Our study investigated whether and, if so, which odonates co-occur with mosquitoes in semi-natural systems, whether odonates colonize mosquito breeding sites of low habitat quality, and whether the presence of odonate larvae leads to a decrease in the density of mosquito larvae. Our results indirectly assess the potential of dragonfly and damselfly larvae for the biological control of mosquito larvae.

Although an earlier inventory of odonates on the University of Ghana Legon campus by Acquah-Lamptey et al. (2013) reported 26 species, we recorded only 5 species during the current study. Bradinopyga strachani was the only species that successfully colonized the experimental containers. This is not surprising as this species, which is also known as a "rock dweller", often breeds in rock pools and open water tanks. The distributional range of B. strachani spans from western Kenya to Guinea and Mali (Clausnitzer and Dijkstra, 2016) covering about a quarter of the area in Africa with malaria (Fig. S6). The species has also been recorded close to villages. Species of the genus Bradinopyga are successful predators of mosquitoes (Venkatesh and Tyagi, 2013a; Varshini and Kanagapapan, 2014), but Sebastian et al. (1990) argued that B. geminata would not be appropriate for mosquito control because it cannot be easily reared to the adult stage in captivity. This argument does not hold for B. strachani, as all 45 larvae collected from the containers survived in the laboratory until emergence as adults. Nevertheless, we want to stress that our aim was not to show that artificial rearing of odonates can be used to multiply potential agents for biological control. We only wanted to show that under natural conditions some odonates colonize artificial containers and that in such containers these odonates reduce the density of mosquito larvae.

In Accra (Ghana), species of Culex, Aedes, and Anopheles can coexist in the same breeding sites, with Culex dominating the mosquito assemblages (Brown et al., 2014). Although it has been reported that Anopheles mosquitoes breed in open, clear, and sunlit pools (Opoku et al., 2007) and Anopheles gambiae larvae develop in permanent, man-made concrete tanks (Mala et al., 2011), we did not find any larvae of this genus in our experimental containers. This absence could be explained by a preference of Anopheles for water bodies close to human dwellings, as observed in Senegal during the rainy season (Diédhiou et al., 2016), as well as the preference of females for black-bottomed habitats and pools with muddy and non-vegetated edges for oviposition (Huang et al., 2005; McCrae, 1983).

The development of $B$. strachani in open containers resulted in the significant decrease in the number of mosquito larvae (Table 2). A significant reduction of mosquito density results from the interaction effect between open containers and time since start of the experiment (variable day). As B. strachani increases in size with time, predation increases leading to a further reduction in mosquito density (Fig. S5). This is in accordance with the observation of Weterings et al. (2015) that the predation rates of odonates increase with body size. Our study does not support the postulates of Sebastian et al. (1990) that it is unlikely that dragonflies and mosquito coexist naturally and that odonates would not be selective enough in their feeding to decrease densities of mosquito populations. Several studies have concluded that dragonflies are active predators of mosquitoes (e.g. Kweka et al., 2011; Sathe and Bhusner, 2010; Saha et al., 2009; Mandal et al., 2008; Chatterjee et al., 2007; Quiroz-Martinez et al., 2005; Stav et al., 2005; Fincke et al., 1997) and our field experiment supports these reports. Although this conclusion is mostly based on laboratory studies, the results of our study indicate that the natural co-occurrence of the predator offers an inexpensive complementary approach for managing mosquito densities. In our opinion, the most inexpensive method is to promote the natural occurrence of odonates. One referee suggested that even adult odonates might contribute to the reduction of mosquitoes by feeding on adult mosquitoes. In general, the diet of adult odonates is very diverse (Sukhacheva, 1996). For example, out of 41 individual wild-caught adult odonates belonging to five species, only four individuals belonging to two species had traces of mosquito remnants in the gut (Pfitzner et al., 2015). Therefore, we expect that adult odonates have little influence on the population size of adult mosquitoes.

The reduction in the density of mosquito larvae in closed containers without predators (Fig. S5) could be due to density-dependent competition (Yoshioka et al., 2012; Roberts and Kokkinn, 2010; Agnew et al., 2002). Densitydependent competition decreases growth rates of larvae, increases larval mortality, delays pupation, and results in the emergence of smaller adults.

A study of predation of Bradinopyga geminata larvae on mosquito larvae in a laboratory experiment in India has shown that this species has a stronger preference for larvae of Culex and Aedes species than for those of Anophe- 
les (Venkatesh and Tyagi, 2013a), which is keeping with the bottom-feeding behaviour of both odonate larvae (Corbet, 1980) and Aedes larvae (Bay, 1974). Although Aedes larvae alter their feeding behaviour in the presence of predators that pose a high risk (Roberts, 2014). Thereby larvae of Aedes switch from bottom feeding to less efficient surface filterfeeding (Roberts, 2012). The larvae of Culex quinquefasciatus, by contrast, easily becomes habituated to the presence of predators (Roberts, 2014).

Shade had a significant positive effect on the density of mosquito larvae, which suggests that microclimate could play a vital role in the success of a natural bio-control programme. First of all, shade could have an adverse effect on the colonization of water bodies by dragonflies (Remsburg et al., 2008; Samways et al., 2005; Clark and Samways, 1996). We observed that adult male dragonflies basked on sunlit containers and defended sunlit containers from other males more than shaded containers. Secondly, shading might result in a reduction of water temperature to the optimum for the survival of mosquito larvae (Mala et al., 2011; Rubio et al., 2011; Wamae et al., 2010; Vezzani and Albicócco, 2009). High water temperatures decrease the survival of mosquito larvae (Christiansen-Jucht et al., 2014). Altogether, this suggests that exposing water-storage containers to sunlight in mosquito-prone regions would increase mortality of mosquito larvae as well as predation (see Christiansen-Jucht et al., 2014). Although covering containers with a fine mesh is the most effective way to keep out mosquitoes, in remote and poor areas where material for covering the containers is not available, keeping the containers in the sun is a cheap possibility to control mosquitoes.

\section{Conclusions}

Although it is believed that odonate larvae do not naturally coexist at high densities with mosquito larvae, and that these predators are not selective enough in their feeding to reduce the density of mosquito larvae, the result of our study showed that $B$. strachani larvae are able to reduce densities of mosquito larvae under semi-natural conditions. This species, which is common around households, has shown its ability to easily breed in water storage containers, which also serve as mosquito breeding reservoirs. Though total covering of water-storage containers is ideal to prevent mosquitoes from breeding in such containers, keeping water-storage containers in sunlit areas to increase water temperature to hinder the development of mosquito larvae and to allow the colonization by $B$. strachani would be promising for suppressing mosquito-borne diseases by vector control in cases where covering of containers is not possible. Promoting the use of such naturally occurring biological control agents of mosquitoes in rural communities would ensure the reduction of pesticide use, savings on pesticide costs, reduced risk of chemical residues on farm products and households, and a safer environment.

Data availability. The dataset has been provided in the Supplement.

Supplement. The supplement related to this article is available online at: https://doi.org/10.5194/we-18-81-2018-supplement.

Competing interests. The authors declare that they have no conflict of interest.

Author contributions. DAL designed and conducted the study under the supervision of RB. RB designed the statistical analyses. DAL wrote the text. RB supervised and commented on text.

Acknowledgements. The authors thank the field-support staff of the Department of Animal Biology and Conservation Science (DABCS), University of Ghana, for their valuable assistance during experimentation and data collection. We are also grateful to Karen A. Brune for the linguistic improvement of the manuscript.

Edited by: Matthias Foellmer

Reviewed by: Carolyn Trietsch and one anonymous referee

\section{References}

Acquah-Lamptey, D., Kyerematen, R., and Owusu, E. O.: Dragonflies (Odonata: Anisoptera) as tools for habitat quality assessment and monitoring at the University of Ghana, Legon Campus, J. Agric. Biodivers. Res., 2, 178-182, 2013.

Aditya, G., Bhattacharya, S., Kundu, N., Saha, G. K., and Raut, S. K.: Predatory efficiency of the water bug Sphaerodema annulatum on mosquito larvae (Culex quinquefasciatus) and its effect on adult emergence, Bioresour. Technol., 95, 169-172, https://doi.org/10.1016/j.biortech.2004.02.007, 2004.

Aditya, G., Ash, A., and Saha, G. K.: Predatory activity of Rhantus sikkimensis and larvae of Toxorhynchites splendens on mosquito larvae in Darjeeling, India, J. Vector Borne Dis., 43, 66-72, 2006.

Aditya, G., Bhattacharyya, S., Kundu, N., Kar, P. K., and Saha, G. $\mathrm{K}$.: Predatory efficiency of the sewage drain inhabiting larvae of Toxorhynchites splendens Wiedemann on Culex quinquefasciatus Say and Armigeres subalbatus (Coquillet) larvae, Southeast Asian J. Trop. Med. Public Health, 38, 799-807, 2007.

Agnew, P., Hide, M., Sidobre, C., and Michalakis, Y.: A minimalist approach to the effects of density dependent competition on insect life-history traits, Eco. Entomol., 27, 396-402, https://doi.org/10.1046/j.1365-2311.2002.00430.x, 2002.

Akram, W. and Ali-Khan, H. A.: Odonate nymphs: generalist predators and their potential in the management of dengue mosquito, Aedes aegypti (Diptera: Culicidae), J. Arthropod-Borne Dis., 10, 253-258, 2016. 
Amha, R.: Impact assessment of rainwater harvesting ponds: the case of Alaba Woreda, Ethiopia, International Water Management Institute, H044078, 2008.

Barton, K.: MuMln: model selection and model averaging based on information criteria (AICc and alike), R package version 1.15.1, 2015.

Bay, E. C.: Predator-prey relationships among aquatic insects, Annu. Rev. Entomol., 19, 441-453, https://doi.org/10.1146/annurev.en.19.010174.002301, 1974.

Bellows, T. S.: Restoring population balance through natural enemy introductions, Biol. Control., 21, 199-205, https://doi.org/10.1006/bcon.2001.0936, 2001.

Blaustein, L. and Bryard, R.: Predation by a cyprinodontid fish, Aphanus mento, on Culex pipiens: effects of alternate prey and vegetation, J. Am. Mosq. Control Assoc., 9, 356-358, 1993.

Brown, C. A., Anang, Y., and Okorie, P. N.: Role of the construction industry in promoting mosquito breeding in and around the Accra metropolis, Ghana, Int. J. Sci. Technol. Res., 3, 94-100, 2014.

Chandra, G., Bhattacharjee, I., Chatterjee, S. N., and Ghosh, A.: Mosquito control by larvivorous fish, Indian J. Med. Res., 127, 13-27, 2008.

Chatterjee, S. N., Ghosh, A., and Chandra, G.: Eco-friendly control of mosquito larvae by Brachytron pratense larva, Environ. Health, 69, 44-49, 2007.

Christiansen-Jucht, C., Parham, P. E., Saddler, A., Koella, J. C., and Basáñez, M. G.: Temperature during larval development and adult maintenance influences the survival of Anopheles gambiae s.s. Parasit, Vectors, 7, 489, https://doi.org/10.1186/s13071-0140489-3, 2014.

Clark, T. E. and Samways, M. J.: Dragonflies (Odonata) as indicators of biotope quality in the Kruger National Park, South Africa, J. Appl. Ecol., 33, 1001-1012, https://doi.org/10.2307/2404681, 1996.

Clausnitzer, V. and Dijkstra, K.-D. B.: Bradinopyga strachani, The IUCN Red List of Threatened Species, 2016, e.T59825A84507333, https://doi.org/10.2305/IUCN.UK.20163.RLTS.T59825A84507333.en, 2016.

Corbet, P. S.: Biology of Odonata, Annu. Rev. Entomol., 25, 189217, 1980.

Cordoba-Aguilar, A. and Lee, M.: Prey size selection by Orthemis ferruginea (Fabricus) larvae (Odonata: Libellulidae) over mosquito instars, Folia Entomol. Mex., 91, 23-30, 1994.

Dejene, G., Habte, T., Teshome, G. M., Meshesha, B., and Akalu, M.: Breeding sites of Aedes aegypti: Potential Dengue Vectors in Dire Dawa, East Ethiopia, Interdiscip. Perspect. Infect. Dis., 8, 706276, https://doi.org/10.1155/2015/706276, 2015.

Diédhiou, S. M., Niang, E. A., Doucoure, S., Samb, B., Konaté, A., Cissokho, S., Ndiaye, A., Wotodjo, A. N., Chauvancy, G., Gadiaga, L., Dotson, E., Thwing, J., Konaté, L., Sokhna, C., and Faye, O.: Distribution and characterization of Anopheline larval habitats in flooded areas of the Dakar suburbs (Senegal), J. Parasitol. Vector Biol., 8, 61-73, https://doi.org/10.5897/JPVB2016.0241, 2016.

Dijkstra, K. D. B. and Clausnitzer, V.: The dragonflies and damselflies of eastern Africa: handbook for all Odonata from Sudan to Zimbabwe. Studies in Afrotropical Zoology, Belgian Royal Museum for Central Africa, 2014.
Fincke, O. M., Yanoviak, S. P., and Hanschu, R. D.: Predation by odonates depresses mosquito abundance in waterfilled tree holes in Panama, Oecologia, 112, 244-253, https://doi.org/10.1007/s004420050307, 1997.

Gosling, R. and Von Seidlein, L.: The Future of the RTS,S/AS01 Malaria Vaccine: An Alternative Development Plan, PLoS Med., 13, e1001994, https://doi.org/10.1371/journal.pmed.1001994, 2016.

Hadfield, J. D.: MCMC methods for multi-response generalized linear mixed models: the MCMCglmm R Package, J. Stat. Softw., 33, 1-22, https://doi.org/10.18637/jss.v033.i02, 2010.

Hammer, A. J., Lane, S. J., and Mahony, M. J.: The role of introduced mosquitofish (Gambusia holbrooki) in excluding the native green and golden bell frog (Litoria auria) from original habitats in South-eastern Australia, Oecologia, 132, 445-452, https://doi.org/10.1007/s00442-002-0968-7, 2002.

Headrick, D. H. and Goeden, R. D.: Biological control as a tool for ecosystem management, Biol. Control., 21, 249-257, 2001.

Hechtel, L. J. and Juliano, S. A.: Effects of a predator on prey metamorphosis: plastic responses by prey or selective mortality?, Ecology, 78, 838-851, https://doi.org/10.1890/00129658(1997)078[0838:EOAPOP]2.0.CO;2, 1997.

Huang, J., Walker, E. D., Giroux, P. Y., Vulule, J., and Miller, J. R.: Ovipositional site selection by Anopheles gambiae: Influences of substrate moisture and texture, Med. Vet. Entomol., 19, 442-450, https://doi.org/10.1111/j.1365-2915.2005.00588.x, 2005.

Jacob, S., Thomas, A. P., and Manju, E. K.: Bio control efficiency of Odonata nymphs on Aedes aegypti larvae, J. Environ. Sc. Toxic Food Tech., 11, 1-4, https://doi.org/10.9790/2402-1109020104, 2017.

Kay, B. H., Cabral, C. P., Sleigh, A. C., Brown, M. D., Ribeiro, R. M., and Vasconcelos, A. W.: Laboratory evaluation of Brazilian Mesocyclops (Copepoda: Cyclopidae) for mosquito control, J. Med. Entomol., 29, 599-602, 1992.

Kelly-Hope, L. A., Yapabandara, A. M. G. M., Wickramasinghe, M. B., Perera, M. D. B., Siyambalagoda, R. R. M. L. R., Herath, P. R. J., Galappaththy, G. N. L., and Hemingway, J.: Spatiotemporal distribution of insecticide resistance in Anopheles culicifacies and Anopheles subpictus in Sri Lanka, Trans. R. Soc. Trop. Med. Hyg., 99, 751-761, https://doi.org/10.1016/j.trstmh.2005.05.008, 2005.

Kokwaro, G.: Ongoing challenges in the management of malaria, Malar. J., 8, S2, https://doi.org/10.1186/1475-2875-8-S1-S2, 2009.

Komak, S. and Crossland, M. R.: An assessment of the introduced mosquito fish (Gambusia affinis holbrooki) as a predator of eggs, hatchlings and tadpoles of native and non-native anurans, Wildl. Res., 27, 185-189, https://doi.org/10.1071/WR99028, 2010.

Kudom, A. A.: Larval ecology of Anopheles coluzzii in Cape Coast, Ghana: water quality, nature of habitat and implication for larval control, Malar. J., 14, 447, https://doi.org/10.1186/s12936-0150989-4, 2015.

Kudom, A. A., Mensah, B. A., Froeschl, G., Boakye, D., and Rinder, H.: Preliminary assessment of the potential role of urbanization in the distribution of carbamate and organophosphate resistant populations of Culex species in Ghana, Parasit. Vectors, 8, 1-10, https://doi.org/10.1186/s13071-014-0621-4, 2015a.

Kudom, A. A., Mensah, B. A., Froeschl, G., Rinder, H., and Boakye, D.: DDT and pyrethroid resistance status 
and laboratory evaluation of bio-efficacy of long lasting insecticide treated nets against Culex quinquefasciatus and Culex decens in Ghana. Acta Trop., 150, 122-130, https://doi.org/10.1016/j.actatropica.2015.07.009, 2015b.

Kumar, R. and Hwang, J. S.: Larvicidal efficiency of aquatic predators: A perspective for mosquito biocontrol, Zool. Stud., 45, 447466, 2006

Kumar, R. and Rao, R.: Predation on mosquito larvae by Mesocyclops thermocyclopoides (Copepoda: Cyclopoida) in presence of alternate prey, Int. Rev. Hydrobiol., 88, 570-581, https://doi.org/10.1002/iroh.200310631, 2003.

Kweka, E. J., Zhou, G., Gilbreath, T. M., Afrane, Y., Nyindo, M., Githeko, A. K., and Yan, G.: Predation efficiency of Anopheles gambiae larvae by aquatic predators in western Kenya highlands, Parasit. Vectors, 4, 1-7, https://doi.org/10.1186/1756-3305-4$128,2011$.

Kweka, E. J., Zhou, G., Munga, S., Lee, M. C., Atieli, H. E., Nyindo, M., Githeko, A. K., and Yan, G.: Anopheline larval habitats seasonality and species distribution: a prerequisite for effective targeted larval habitats control programmes, PLoS One, 7, e52084, https://doi.org/10.1371/journal.pone.0052084, 2012.

Lundkvist, E., Landin, J. M., and Svensson, C.: Diving beetles (Dytiscidae) as predators of mosquito larvae (Culicidae) in field experiments and in laboratory tests of prey preference, Bull. Entomol. Res., 93, 219-226, https://doi.org/10.1079/BER2003237, 2003

Mala, A. O., Irungu, L. W., Shililu, J. I., Muturi, E. J., Mbogo, C. C., Njagi, J. K., and Githure, J. I.: Dry season ecology of Anopheles gambiae complex mosquitoes at larval habitats in two traditionally semi-arid villages in Baringo, Kenya, Parasit. Vectors, 4, 25, https://doi.org/10.1186/1756-3305-4-25, 2011.

Mandal, S. K., Ghosh, A., Bhattacharjee, I., and Chandra, G.: Biocontrol efficiency of odonate nymphs against larvae of the mosquito, Culex quinquefasciatus Say, 1823, Acta Trop., 106, 109-114, https://doi.org/10.1016/j.actatropica.2008.02.002, 2008.

Marten, G. G. and Reid, W.: Cyclopoids copepods, J. Am. Mosq. Control Assoc., 23, 65-92, https://doi.org/10.2987/8756971X(2007)23[65:CC]2.0.CO;2, 2007.

Marten, G. G., Borjas, G., Cush, M., Fernandez, E., and Reid, J. W.: Control of larval Aedes aegypti (Diptera: Culicidae) by cyclopoid copepod in peridomestic breeding containers, J. Med. Entomol., 31, 36-44, 1994.

Mathavan, S.: Satiation time and predatory behaviour of the dragonfly nymph Mesogomphus lineatus, Hydrobiologia, 50, 55-64, 1976.

Mawejje, H. D., Wilding, C. S., Rippon, E. J., Hughes, A., Weetman, D., and Donnelly, M. J.: Insecticide resistance monitoring of field-collected Anopheles gambiae s.l. populations from Jinja, Eastern Uganda, identifies high levels of pyrethroid resistance, Med. Vet. Entomol., 27, 276-283, https://doi.org/10.1111/j.1365-2915.2012.01055.x, 2013.

McCrae, A. W. R.: Oviposition by African malaria vector mosquitoes I. Temporal activity pattern of caged, wild-caught, freshwater Anopheles gambiae Giles sensu lato, Ann. Trop. Med. Parasitol., 77, 615-625, 1983.

Mijares, A. S., Pérez Pacheco, R., Tomás Martínez, S. H., Cantón, L. E., and Ambrosio, G. F.: The Romanomermis iyengari parasite for Anopheles pseudopunctipennis suppression in natural habitats in Oaxaca State, Mexico. Rev. Panam Salud Publica., 5, 23-28, 1999.

Ministry of Health and Ghana Health Service: Ghana Malaria programme review: final report, National malaria control programme, 2013.

Miura, T. and Takahashi, R. M.: A laboratory study of predation by damselfly nymphs Enallagma civile upon mosquito larvae Culex tarsalis, J. Am. Mosq. Control Assoc., 4, 129-131, 1988.

Mohamed, A. A.: Study of larvivorous fish for malaria vector control in Somalia, East Mediterr. Health J., 9, 618-626, 2003.

Mokany, A. and Shine, R.: Biological warfare in the garden pond: tadpoles suppress the growth of mosquito larvae, Ecol. Entomol., 28, 102-108, https://doi.org/10.1046/j.1365-2311.2003.00476.x, 2003.

Nega, H.: Training manual on Rainwater Harvesting and Utilization Techniques, Addis Ababa, Ethiopia, 2005.

Neng, W., Shusen, W., Guangxin, H., Rongman, X., Guangkun, T., and Chen, Q.: Control of Aedes aegypti larvae in household water containers by Chinese cat fish, Bull. World Hlth. Org., 65, 503506, 1987.

Nyamah, M. A., Sulaiman, S., and Omar, B.: Field observation on the efficacy of Toxorhynchites splendens (Wiedemann) as a biocontrol agent against Aedes albopictus (Skuse) larvae in a cemetery, Trop. Biomed., 28, 312-319, 2011.

Opoku, A. A., Ansa-Asare, O. D., and Amoako, J.: The occurrences and habitat characteristics of mosquitoes in Accra, Ghana, W. Afr. J. App. Ecol., 11, 99-107, 2007.

Panogadia-Reyes, C. M., Cruz, E. I., and Bautista, S. L.: Philippine species of Mesocyclops (Crustacea: Copepoda) as a biological control agent of Aedes aegypti (Linnaeus), Dengue Bull., 28, 174-178, 2004.

Perez-Pacheco, R. and Flores, G.: Mass production of mermithid nematode parasites of mosquito larvae in Mexico, J. Nematol. 37, 388, ISSN: 0022-300X, 2005.

Pfitzner, W. P., Beck, M., Weitzel, T., and Becker, N.: The Role of Mosquitoes in the Diet of Adult Dragon and Damselflies (Odonata), J. Am. Mosq. Control Assoc., 31, 187-189, https://doi.org/10.2987/14-6476R, 2015.

Quiroz-Martinez, H. and Rodriguez-Castro, A.: Aquatic insects as predators of mosquito larvae, J. Am. Mosq. Control Assoc., 23, 110-117, https://doi.org/10.2987/8756971X(2007)23[110:AIAPOM]2.0.CO;2, 2007.

Quiroz-Martínez, H., Rodríguez-Castro, V. A., Solís-Rojas, C., and Maldonado-Blanco, M. G.: Predatory capacity and prey selectivity of nymphs of the dragonfly Pantala hymenaea, J. Am. Mosq. Control Assoc., 21, 328-330, https://doi.org/10.2987/8756971X(2005)21[328:PCAPSO]2.0.CO;2, 2005.

Raghavendra, K., Sharma, P., and Dash, A. P.: Biological control of mosquito populations through frogs: opportunities \& constrains, Indian J. Med. Res., 128, 22-25, 2008.

Rämi, H.: Ponds filled with challenges. Water harvesting - experiences in Amhara and Tigray, UN OCHA-Ethiopia, 2003.

R Development Core Team: R: A Language and Environment for Statistical Computing. Vienna, Austria: R Foundation for Statistical Computing, 2016.

Remsburg, A. J., Anders, C. O., and Samways, M. J.: Shade alone reduces adult dragonfly (Odonata: Libellulidae) abundance, J. Insect Behav., 21, 460-468, https://doi.org/10.1007/s10905-0089138-z, 2008. 
Roberts, D.: Rapid habituation by mosquito larvae to predator kairomones, J. Vector Ecol., 39, 355-360, https://doi.org/10.1111/jvec.12111, 2014.

Roberts, D. and Kokkinn, M.: Larval crowding effects on the mosquito Culex quinquefasciatus: physical or chemical?, Entomol. Exp. Appl., 135, 271-275, https://doi.org/10.1111/j.15707458.2010.00993.x, 2010.

Roberts, D.: Responses of three species of mosquito larvae to the presence of predatory dragonfly and damselfly larvae, Entomol. Exp. Appl., 145, 23-29, https://doi.org/10.1111/j.15707458.2012.01300.x, 2012.

Rodriguez-Castro, V. A., Quiroz-Martinez, H., SolisRojas, H., and Tejada, L. O.: Mass rearing and egg release of Buenos scimitar Bare as biocontrol of larval Culex quinquefasciatus, J. Am. Mosq. Control Assoc., 22, 123-125, https://doi.org/10.2987/8756971X(2006)22[123:MRAERO]2.0.CO;2, 2006.

Rubio, A., Cardo, M. V., and Vezzani, D.: Tire-breeding mosquitoes of public health importance along an urbanisation gradient in Buenos Aires, Argentina, Mem. Inst. Oswaldo Cruz, Rio de Janeiro, 106, 678-684, https://doi.org/10.1590/S0074$02762011000600006,2011$.

Saha, N., Aditya, G., Bal, A., and Saha, G. K.: A comparative study of predation of three aquatic heteropteran bugs on Culex quinquefasciatus larvae, Limnology, 8, 73-80, https://doi.org/10.1007/s10201-006-0197-6, 2007.

Saha, N., Aditya, G., and Saha, G. K.: Habitat complexity reduces vulnerability of preys: an experimental analysis using aquatic insect predators and dipteran immature, J. Asia Pac. Entomol., 12, 233-239, https://doi.org/10.1016/j.aspen.2009.06.005, 2009.

Saha, N., Aditya, G., Banerjee, S., and Saha, G. K.: Predation potential of odonates on mosquito larvae: Implications for biological control, Biol. Control, 63, 1-8, https://doi.org/10.1016/j.biocontrol.2012.05.004, 2012.

Samways, M. J. Taylor, S., and Tarboton, W.: Extinction reprieve following alien removal, Conserv. Biol., 19, 1329-1330, https://doi.org/10.1111/j.1523-1739.2005.00176.x, 2005.

Sathe, T. V. and Bhusnar, A. R.: Biodiversity of mosquitovorous dragonflies (Order: Odonata) from Kolhapur district including Western Ghats, Biol. Forum Int. J., 2, 38-41, 2010.

Sebastian, A., Thu, M. M., Kyaw, M., and Sein, M. M.: The use of dragonfly larvae in the control of Aedes aegypti, Southeast Asian J. Trop. Med. Public Health, 11, 104-107, 1980.

Sebastian, A., Sein, M. M., Thu, M. M., and Corbet, P. S.: Suppression of Aedes aegypti (Diptera: Culicidae) using augmentative release of dragonfly larvae (Odonata: Libellulidae) with community participation in Yangon, Myanmar, Bull. Entomol. Res., 80, 223-232, https://doi.org/10.1017/S0007485300013468, 1990.

Singh, R. K., Dhiman, R. C., and Singh, S. P.: Laboratory studies on the predatory potential of dragonfly nymphs on mosquito larvae, J. Commun. Dis., 35, 96-101, 2003.

Sivagnaname, N.: A novel method of controlling a dengue mosquito vector, Aedes aegypti (Diptera: Culicidae) using an aquatic mosquito predator, Diplonychus indicus (Hemiptera: Belostomatidae) in tyres, Dengue Bull., 33, 148-160, 2009.

Spielman, A., Kitron, U., and Pollack, R. J.: Time limitation and the role of research in the worldwide attempt to eradicate malaria, J. Med. Entomol., 30, 6-19, 1993.
Stav, G., Blaustein, L., and Margalit, Y.: Influence of nymphal Anax imperator (Odonata: Aeshnidae) on oviposition by the mosquito Culiseta longiareolata (Diptera: Culicidae) and community structure in temporary pools, J. Vector Ecol., 25, 190202, 2000.

Stav, G., Blaustein, L., and Margalit, Y.: Individual and interactive effects of a predator and controphic species on mosquito populations, Ecol. Appl., 15, 587-598, https://doi.org/10.1890/03-5191, 2005.

Sukhacheva, G. A.: Study of the natural diet of adult dragonflies using immunological methods, Odonatologica, 25, 397-404, 1996.

Varshini, R. A. and Kanagappan, M.: Effect of quantity of water on the feeding efficiency of dragonfly Nymph-Bradynopyga geminata (Rambur), J. Entomol. Zool Stud., 2, 249-252, 2014.

Venkatesh, A. and Tyagi, B. K.: Capture efficiency of Bradinopyga geminata (Odonata: Libellulidae) against larvae of Aedes aegypti, Culex tritaeniorhynchus and Anopheles stephensi in laboratory condition, J. Basic Appl. Biol., 7, 21-26, 2013a.

Venkatesh, A. and Tyagi, B. K.: Predatory potential of Bradinopyga geminata and Ceriagrion coromandelianum on dengue vector Aedes aegypti under controlled conditions (Anisoptera; Libellulidae; Zygoptera: Coenagrionidae; Diptera: Culicidae), Odonatologica, 42, 139-149, 2013b.

Vezzani, D. and Palbicócco, A.: The effect of shade on the container index and pupal productivity of the mosquitoes Aedes aegypti and Culex pipiens breeding in artificial containers, Med. Vet. Entomol., 23, 78-84, https://doi.org/10.1111/j.13652915.2008.00783.x, 2009.

Waktola, D. K.: Malaria and pond-based rainwater harvesting linkages in the fringes of central highland Ethiopia, Rural Rem. Health, 8, 956 (online), available at: www.rrh.org.au/journal/ article/956, 2008.

Wamae, P. M., Githeko, A. K., Menya, D. M., and Takken, W.: Shading by napier grass reduces malaria vector larvae in natural habitats in Western Kenya highlands, Ecohealth, 7, 485-497, https://doi.org/10.1007/s10393-010-0321-2, 2010.

Wang, C. H.: Laboratory comparative evaluation of larvivorous fishes as dengue fever vector control agents, Chin. J. Publ. Hlth., 17, 458-467, 1998.

Ware, G. W.: Effects of pesticides on nontarget organisms, in: Residue Reviews: Residues of pesticides and other contaminants in the total environment, edited by: Gunther, F. A. and Gunther, J. D., New York, Springer New York, 173-201, 1980.

Weterings, R., Umponstira, C., and Buckley, H. L.: Predation rates of mixed instar Odonata naiads feeding on Aedes aegypti and Armigeres moultoni (Diptera: Culicidae) larvae, J. Asia Pac. Entomol., 18, 1-8, https://doi.org/10.1016/j.aspen.2014.10.008, 2015.

Wickham, H.: tidyr: easily tidy data with 'spread()' and 'gather()' Functions, R package version 0.6.1, https://CRAN.R-project.org/ package $=$ tidyr, 2017.

World Health Organization: Vaccines and vaccination against yellow fever: WHO position paper - June 2013, Wkly. Epidemiol. rec., 88, 269-284, 2013.

World Health Organization: Vector - borne diseases, available at: http://www.who.int/mediacentre/factsheets/fs387/en/, last access: 26 October $2016 \mathrm{a}$.

World Health Organization: World malaria report 2016, Geneva, $2016 b$. 
World Health Organization: Global programme to eliminate lymphatic filariasis: progress report, 2015, Wkly. Epidemiol. Rec., 91, 441-460, 2016c.

World Health Organization: Dengue vaccine: WHO position paper - July 2016, Wkly. Epidemiol. Rec., 91, 349-364, 2016d.

World Health Organization: Chikungunya: Fact sheet, available at: http://www.who.int/mediacentre/factsheets/fs327/en/, last access: 5 May 2017.
Yoshioka, M., Couret, J., Kim, F., Mcmillan, J., Burkot, T. R., Dotson, E. M., Kitron, U., and Vazquez-Prokopec, G. M.: Diet and density dependent competition affect larval performance and oviposition site selection in the mosquito species Aedes albopictus (Diptera: Culicidae), Parasit. Vectors, 5, 225, https://doi.org/10.1186/1756-3305-5-225, 2012. 